\title{
Influência do transporte e mudança de local de manejo nas variáveis fisiológicas e produtivas de cabras Alpinas
}

[Physiologic and productive responses of Alpine goats submitted to transportation to a new dairy location]

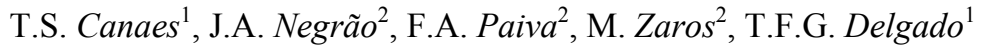 \\ ${ }^{1}$ Aluno de pós-graduação - FCAV-UNESP - Jaboticabal, SP \\ ${ }^{2}$ Faculdade de Zootecnia e Engenharia de Alimentos - USP - Pirassununga, SP
}

\begin{abstract}
RESUMO
Estudaram-se o efeito do transporte e a mudança de local de manejo sobre a produção e a composição do leite e sobre as variáveis fisiológicas, utilizando-se 12 cabras da raça Alpina em final de lactação. Semanalmente, foram mensuradas a produção e composição do leite e a contagem de células somáticas, além do volume do leite residual após administração de ocitocina. Foram colhidas amostras de sangue para dosagem hormonal (cortisol) e enzimática (glicose) no plasma no dia do transporte: antes (7h10min) e após $(8 \mathrm{~h} 20 \mathrm{~min}, 8 \mathrm{~h} 30 \mathrm{~min}$ e $10 \mathrm{~h} 30 \mathrm{~min})$ o transporte. Nas três semanas subsequentes ao transporte, também foram colhidas amostras de sangue às $8 \mathrm{~h} 20 \mathrm{~min}$. Obtiveram-se teores mais elevados $(\mathrm{P}<0,05)$ de cortisol e glicose após o transporte e a mudança de local de manejo, e menor produção de leite $(\mathrm{P}<0,05)$ um dia após o evento. Porcentagem de gordura $(\mathrm{P}<0,05)$ e contagem de células somáticas apresentaram diferenças significativas $(\mathrm{P}<0,05)$ após o transporte. Os resultados permitem concluir que o transporte é um agente estressor que pode, momentaneamente, influenciar a produção animal.
\end{abstract}

Palavras-chave: cabra, cortisol, estresse, leite residual, produção de leite

\begin{abstract}
The effects of transportation and reallocation on milk production and composition and physiological responses were studied in 12 late-lactation Alpine goats. Weekly, somatic cell count, milk production and composition, and residual milk volume (after administration of oxytocin) were monitored. Blood samples were taken for hormonal (cortisol) and enzymatic dosages (glucose) in plasma on the day of transportation: before (7h10min) and after transportation (8h20min, 8h30min, and 10h30min). During the three weeks after transportation, blood samples were also taken at 8 h20min. Higher levels $(P<0.05)$ of cortisol and glucose after transportation and reallocation were observed and milk yield was significantly lower $(P<0.05)$ one day after them. Milk fat percentage and somatic cell count $(P<0.05)$ were higher after transportation. Results allow concluding that transportation is a stressor agent that may momentarily influence animal production.
\end{abstract}

Keywords: goat, cortisol, stress, residual milk, milk production

\section{INTRODUÇÃO}

Há um interesse em muitos países de aprofundar as pesquisas as pesquisas sobre os efeitos do transporte e do manejo no bem-estar dos animais (Grandin, 1997). Muitas pesquisas estão sendo desenvolvidas com o objetivo de quantificar a severidade do estresse imposto e identificar circunstâncias e métodos aceitáveis para minimizar os efeitos adversos deste tipo de manejo (Grandin, 2000). O transporte pode desencadear alterações fisiológicas no animal como aumento de frequência respiratória, batimentos cardíacos, temperatura corporal e da pele, além do aumento dos níveis de cortisol, influenciando a produção de leite e consequentes

Recebido em 24 de setembro de 2008

Aceito em 18 de maio de 2009

E-mail: tscanaes@yahoo.com.br 
alterações de sua qualidade (Yagi et al., 2004). Em geral, níveis de cortisol têm sido mensurados em estudos voltados à resposta de animais domésticos ao estresse (Sanhouri et al., 1989; Nwe et al., 1996; Gygax et al., 2008). Quando a rotina da ordenha é quebrada, pode haver aumento dos níveis plasmáticos de cortisol, inibição da liberação de ocitocina e, consequentemente, inibição da ejeção do leite, mesmo para vacas especializadas (Negrão e Marnet, 2006).

Além de inibir a cinética de ejeção do leite (Bruckmaier et al., 1993), o estresse aumenta o volume de leite residual em decorrência da inibição da liberação de ocitocina endógena, por exemplo, a presença de um tratador aversivo durante a ordenha pode aumentar em $70 \%$ o leite residual (Rushen et al., 2001).

O objetivo deste trabalho foi avaliar as respostas fisiológicas e produtivas de cabras da raça Alpina submetidas ao transporte e à mudança de local de manejo.

\section{MATERIAL E MÉTODOS}

Foram utilizadas 12 cabras da raça Alpina, uniformes quanto à produção de leite e escore corporal, na segunda lactação, com produção média de leite de $1380 \pm 160 \mathrm{ml}$, peso de $62,25 \pm 1,80 \mathrm{~kg}$. Os animais experimentais permaneceram em sistema semi-confinado com acesso a um piquete de capim-tanzânia (Panicum maximum, Jacq.) com baixa disponibilidade de matéria verde. A silagem de milho e o concentrado à base de milho grão, farelo de soja, soja tostada e calcário foram fornecidos após a ordenha da manhã seguindo recomendações do NRC (Nutrient..., 2007). O sal mineral e a água foram fornecidos à vontade.

Durante todo o período experimental, os animais foram ordenhados em sala de ordenha, uma vez ao dia às $6 \mathrm{~h} 30 \mathrm{~min}$. A ordenhadeira mecânica com seis conjuntos de teteiras foi regulada para manter 180 pulsações por minuto com vácuo ajustado a $44 \mathrm{kPa}$. Após o término da ordenha, foram administrados, semanalmente, $2,5 \mathrm{~mL}$ de ocitocina $(10 \mathrm{UI} / \mathrm{mL})$, via intramuscular, e após cinco minutos as cabras foram novamente ordenhadas para a obtenção da fração do leite residual, o qual foi expresso em quantidade $(\mathrm{mL})$ e em porcentagem do leite total. Os teores de proteína, gordura, lactose, sólidos totais e contagem de células somáticas foram determinados por meio do contador eletrônico Bentley $2000^{1}$ e pelo Somacount $300^{2}$, respectivamente. Cada amostra de $50 \mathrm{~mL}$ de leite foi conservada com uma pastilha do conservante bronopol (2-bromo-2-nitropropano-1,3-diol) e analisada em até sete dias após a colheita.

Os animais transportados em caminhão especializado tipo gaiola (carroceria aberta), durante 60 minutos, percorreram $35 \mathrm{~km}$ e foram alojados em instalações desconhecidas por eles, constituindo um novo ambiente de ordenha.

Para análise do cortisol e glicose, o sangue foi colhido da veia jugular das cabras presas no canzil nos seguintes momentos: 1- antes do transporte (10 minutos antes do evento, às 7h10min); 2- após o transporte, ao desembarque (8h20min), aos 10min (8h30min) e aos 120min após o desembarque (10h30min). O sangue também foi colhido na semana anterior (05/08), no dia posterior ao transporte (11/08) e nas semanas subsequentes $(18,25$ e $31 / 08)$, sempre no horário do desembarque ( $8 \mathrm{~h} 20 \mathrm{~min})$.

Nas colheitas de sangue, utilizaram-se tubos heparinizados e a vácuo, conservados em recipiente com gelo. Posteriormente, o sangue foi centrifugado por 15 minutos, a $3000 \mathrm{~g}$, a $15^{\circ} \mathrm{C}$ de temperatura para obtenção do plasma. O plasma foi conservado a $-20^{\circ} \mathrm{C}$ para posteriores dosagens fisiológicas de cortisol e glicose. Foram utilizados kits para dosagem imunoenzimática (EIA) de cortisol ${ }^{3}$ e glicose plasmática ${ }^{4}$.

Para as análises estatísticas, utilizou-se o PROC GLM do SAS/2004, por meio de análise de variância e, para os contrastes entre as médias, utilizou-se o teste Tukey. O nível de significância utilizado foi o de $5 \%$, e todos os resultados experimentais foram apresentados com médias e o erro-padrão médio (EPM).

\footnotetext{
${ }^{1}$ Infrared Analyser for milk, Bentley Instruments Incorporated - Chaska, Minnesota, EUA.

${ }^{2}$ Bentley Instruments Incorporated - Chaska, Minnesota, EUA.

${ }^{3}$ Diagnostic Systems Laboratories - DSL-10-2000 Active $^{\circledR}$ Webster, Texas, EUA.

${ }^{4}$ Laborlab - Guarulhos, São Paulo, Brasil.
} 


\section{RESULTADOS E DISCUSSÃO}

As concentrações de cortisol e glicose nas cabras submetidas ao transporte e um novo ambiente de manejo encontram-se na Fig. 1. As curvas de cortisol e glicose apresentaram perfis semelhantes, sendo que os níveis basais do cortisol e da glicose (10min antes do transporte, colhido às $7 \mathrm{~h} 10 \mathrm{~min})$ aumentaram significativamente $(\mathrm{P}<0,05)$ e progressivamente logo após o transporte, atingindo, respectivamente, os picos de $18,7 \pm 2,41 \mathrm{ng} / \mathrm{mL}$ e $160,9 \pm 13,3 \mathrm{mg} / \mathrm{dL} 10 \mathrm{~min}$ após o desembarque.
Entretanto, esses níveis diminuíram, alcançando valores semelhantes ao basal, 120 minutos após o transporte. Estes resultados demonstram que o transporte e a mudança de ambiente de manejo foram agentes estressores. Segundo McDonald e Pineda (1989), caprinos adultos, em condições normais, apresentam valores de cortisol que podem variar de 8 a 19ng/mL. Nwe et al. (1996) relataram que os níveis de cortisol em cabras aumentaram 30min após o transporte, alcançando o pico em uma hora, e que os valores basais foram alcançados três horas após o fím do transporte.

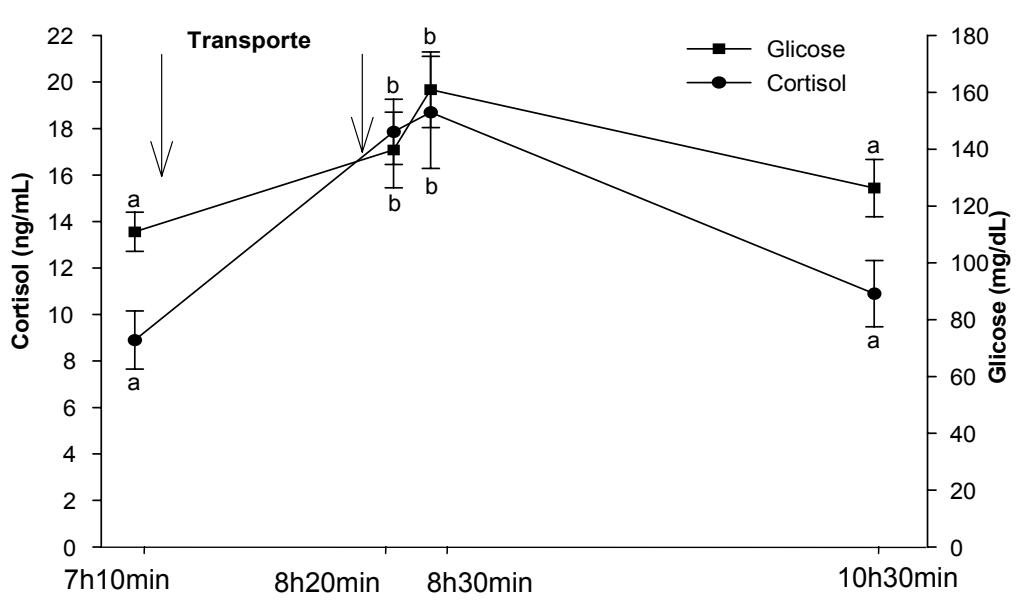

Figura 1. Concentrações de cortisol e glicose em cabras da raça Alpina submetidas ao transporte e à mudança de ambiente de manejo. Valores seguidos por letras distintas diferem entre si $(\mathrm{P}<0,05)$.

Animais transportados por longas distâncias e realocados em um novo ambiente apresentaram alterações importantes nos níveis de cortisol (Pearson e Kilgour, 1980; Odore et al., 2004; Ishiwata et al., 2008). Assim, o aumento observado nas concentrações de cortisol após o transporte indica que esse manejo é muito estressante para os animais (Grigor et al., 1997; Adamante et al., 2008), comparável a outros tipos de estresse causados pelo manejo (Blackshaw, 1984; Paiva et al., 2006).

O aumento da glicose sanguínea em situações de estresse está relacionado ao acréscimo da taxa de gliconeogênese e à diminuição moderada da utilização do açúcar pelas células (Chrousos e Gold, 1992; Peters et al., 2007). Nwe et al. (1996) também observaram aumentos semelhantes nos níveis de glicose e cortisol sanguíneos em cabras submetidas ao transporte.
As concentrações de cortisol e glicose (Fig. 2) foram influenciadas pelo transporte. Houve diferença significativa $(\mathrm{P}<0,05)$ nas dosagens de cortisol em função do dia de colheita, sendo o maior nível $(17,86 \pm 1,40 \mathrm{ng} / \mathrm{mL})$ observado no dia do transporte.

Ainda, na Fig. 2, observa-se diferença significativa $(\mathrm{P}<0,05)$ para glicose no dia do transporte quando comparada às semanas anteriores e subsequentes. Pode-se inferir que o transporte e a mudança de ambiente de manejo alteraram o metabolismo dos animais, porém nas semanas subsequentes, a taxa metabólica retomou aos valores próximos aos basais.

O transporte e a mudança de local de manejo influenciaram a produção de leite até uma semana após o evento $(\mathrm{P}<0,05) \quad$ (Fig. 3), sugerindo que os animais habituaram-se ao novo ambiente, recuperando a produção mensurada antes do transporte. 


\section{Canaes et al.}

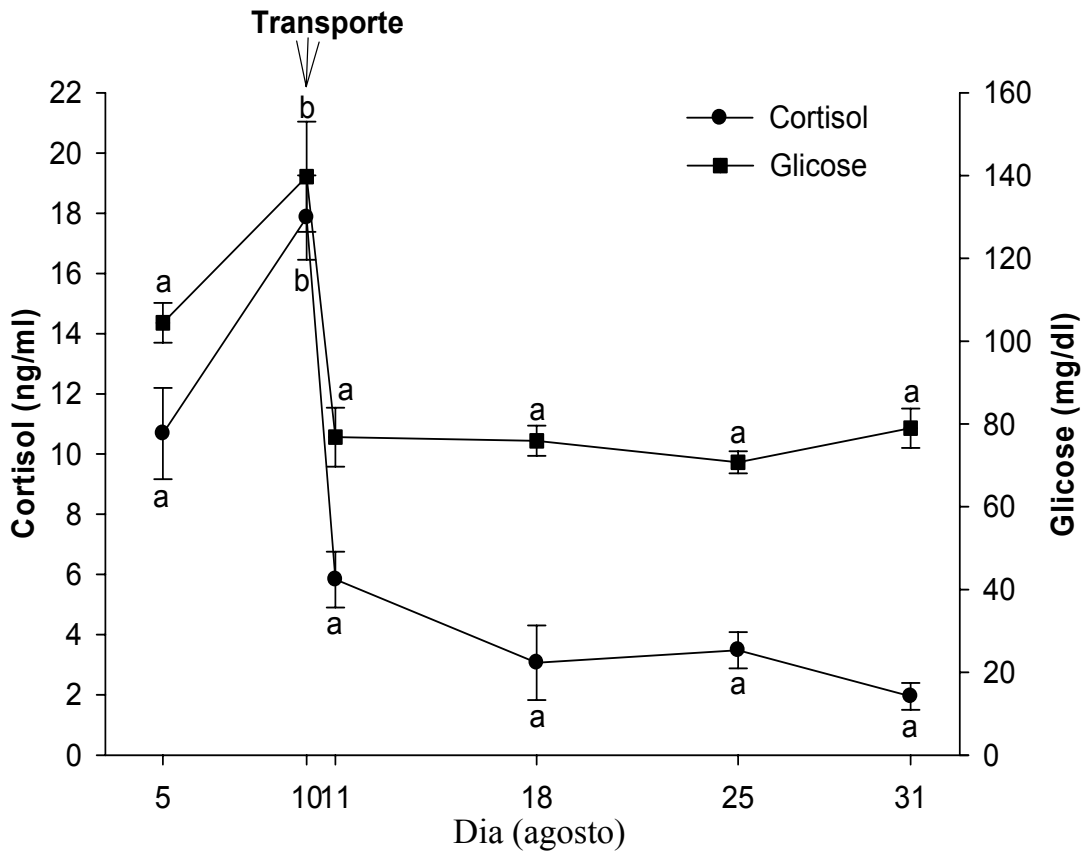

Figura 2. Concentrações de cortisol e glicose durante os dias experimentais que antecederam e sucederam o transporte e a mudança de ambiente de manejo em cabras da raça Alpina. Valores seguidos por letras distintas diferem entre si $(\mathrm{P}<0,05)$.

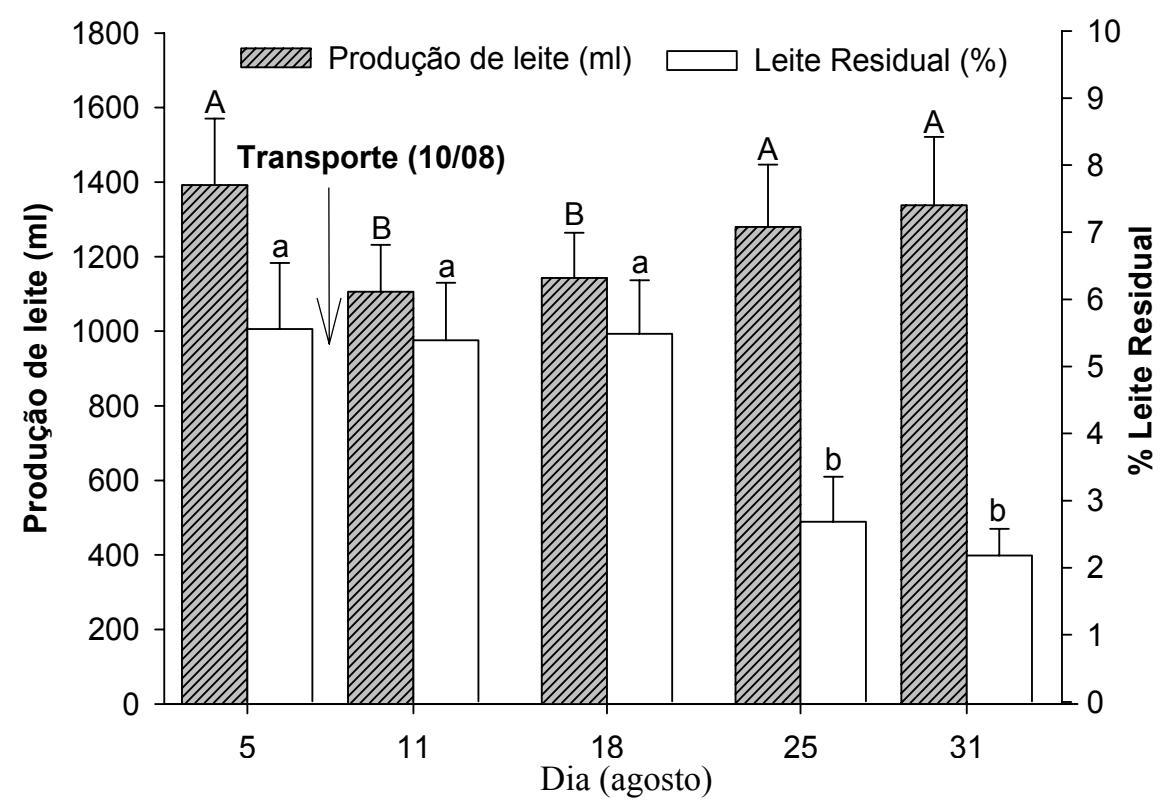

Figura 3. Porcentagem de leite residual após administração de ocitocina em cabras da raça Alpina submetidas ao transporte e à mudança de ambiente de manejo. Valores seguidos por letras maiúsculas distintas nas colunas hachuradas e letras minúsculas distintas nas colunas em branco diferem entre si $(\mathrm{P}<0,05)$. 
Também houve diferença significativa $(\mathrm{P}<0,05)$ para a interação dia/animal sobre a porcentagem do leite residual. Isto sugere que os animais habituaram-se ao novo ambiente duas semanas após o transporte e a mudança de local de ordenha, quando apresentaram menor porcentagem de leite residual. O volume de leite residual foi inversamente relacionado à produção total de leite, fato já citado por Peaker e Blatchford (1988) e Marnet e McKusic (2001), e diretamente relacionado com a liberação de cortisol, também observado por Porcionato et al. (2005). Entretanto, se não houver liberação de ocitocina, a ejeção do leite é prejudicada, o que foi observado nas duas semanas subsequentes ao transporte.

A composição físico-química e a contagem de células somáticas do leite encontram-se na Tab. 1. A gordura foi o único componente que apresentou diferença significativa $(\mathrm{P}<0,05)$ entre as semanas do transporte. Os dados da literatura relatam alterações semelhantes na composição do leite em animais submetidos ao estresse térmico, causando diminuição nos teores de sólidos totais, proteína e gordura (Giesecke, 1985; Du Preez, 2000; González e Silva, 2003). A composição alterada no teor de gordura do leite pode ser explicada pelo estresse sofrido pelos animais, resultando em diminuição na síntese, absorção e mobilização dos metabólitos a partir do trato digestivo, fígado e tecido adiposo, e sua utilização pela glândula mamária (Head, 1989).

O transporte e a mudança de ambiente promoveram aumento significativo $(\mathrm{P}<0,05)$ na contagem de células somáticas uma semana após o evento. Estudos mostraram que o estresse induzido por transporte acompanhado da mudança para novos ambientes de manejo prejudica a resposta imunológica, predispondo os animais a doenças (Thiry et al., 1987), devido à liberação de cortisol e catecolaminas (Fauci, 1979; Crary et al., 1983; Landmann et al., 1984), e pode diminuir a competência imunológica e induzir ao aumento de perdas de células secretoras, ocasionando elevação na contagem de células somáticas (Yagi et al., 2004). Contudo, não houve constatação de mastite clínica no presente experimento. Relação inversa entre produção de leite e contagem de células somáticas foi observada no presente estudo após o transporte. Alguns autores também observaram a mesma relação em outras situações estressantes (Hinckley, 1983; Zeng e Escobar, 1995; Grasso et al., 2007).

Tabela 1. Teores de gordura (média e erro-padrão médio), proteína e lactose e contagem de células somáticas em cabras da raça Alpina submetidas ao transporte e à mudança de local de ordenha

\begin{tabular}{cccc}
\hline Variável & Antes & No dia do transporte & Após * \\
\hline Gordura $(\%)$ & $3,89 \pm 0,18 \mathrm{a}$ & $3,48 \pm 0,34 \mathrm{~b}$ & $3,52 \pm 0,24 \mathrm{~b}$ \\
Proteína $(\%)$ & $3,48 \pm 0,04 \mathrm{a}$ & $3,47 \pm 0,06 \mathrm{a}$ & $3,46 \pm 0,06 \mathrm{a}$ \\
Lactose $(\%)$ & $4,20 \pm 0,15 \mathrm{a}$ & $4,41 \pm 0,01 \mathrm{a}$ & $4,11 \pm 0,11 \mathrm{a}$ \\
Contagem de células somáticas & $1915 \pm 715 \mathrm{~b}$ & $2847 \pm 565 \mathrm{~b}$ & $6165 \pm 637 \mathrm{a}$
\end{tabular}

*Média dos dias subsequentes ao evento.

Médias seguidas de letras distintas na linha diferem entre si $(\mathrm{P}<0,05)$.

\section{CONCLUSÃO}

O transporte e a mudança de ambiente de manejo induziram o estresse momentâneo promovendo aumento da contagem de células somáticas e redução temporária da produção de leite de cabras até uma semana após o evento. Assim, modificações nas instalações e no manejo de ordenha devem ser evitadas sempre que possível, a fim de se evitar prejuízos ao produtor.

\section{REFERÊNCIAS BIBLIOGRÁFICAS}

ADAMANTE, W.B.; NUÑER, A.P.O.; BARCELlOS, L.J.G. et al. Stress in Salminus brasiliensis fingerlings due to different densities and times of transportation. Arq. Bras. Med. Vet. Zootec., v.60, p.755-761, 2008.

BLACKSHAW, J.K. Notes on some topics in applied animal behaviour. Brisbane: University of Queensland, 1984. 131p.

BRUCKMAIER, R.M.; SCHAMS, K.; BLUM, J.W. Milk removal in familiar and unfamiliar surroundings concentrations of oxytocin, prolactin, cortisol and $\beta$ endorphin. J. Dairy Res., v.60, p.449-456, 1993. 
CHROUSOS, G.O.; GOLD, P.W. The concept the stress system disorders. Overview of physical and behavioural homeostasis. J. Am. Med. Assoc., v.267, p.1244-1252, 1992.

CRARY, B.; BORYSENKO, M.; SUTHERLAND D.C. et al. Decrease in mitogen responsiveness of mononuclear cells from peripheral blood after epinephrine administration in humans. J. Immunol., v.130, p.694-697, 1983.

DU PREEZ, J.H. Parameters for the determination and evaluation of heat stress in dairy cattle in South Africa. $J$. Vet. Res., v.67, p.263-271, 2000.

FAUCI, A.S. Immunosuppressive and anti-inflammatory effects of glucocorticoids. In: BAXTER, J.D.; ROUSSEAU, G.G. (Ed.). Glucocorticoid hormone action. Berlin: SpringerVerlag, 1979. p.449-465.

GIESECKE, W.H. The effect of stress on udder health of dairy cows. Onderstepoort J. Vet. Res., v.52, p.175-193, 1985.

GONZÁLEZ, F.H.D.; SILVA, S.C. Introdução à bioquímica clínica veterinária. Porto Alegre: UFRGS, 2003. 198p.

GRANDIN, T. Assesment of stress during handling and transport. J. Anim. Sci., v.75, p.249-257, 1997.

GRANDIN, T. Livestock handling and transport. Wasllingford: CABI, 2000. p.63-85.

GRASSO, F.; DE ROSA, G.; NAPOLITANO, F. et al. Entrance order and side preference of dairy cows in the milking parlour. Ital. J. Anim. Sci., v.6, p.187-194, 2007.

GRIGOR, P.N.; GODDARD, P.L.; MacDONALD, A.J. et al. Effects of the duration of lairage following transportation on the behaviour and physiology of farmed red deer. Vet. Rec., v.140, p.8-12, 1997.

GYGAX, L.; NEUFFER, I.; KAUFMANN, C. et al. Restlessness behaviour, heart rate and heart-rate variability of dairy cows milked in two types of automatic milking systems and auto-tandem milking parlours. Appl. Anim. Behav. Sci., v.109, p.167-179, 2008.

HEAD, H.H. The strategic use of the physiological potential of the dairy cow. In: SIMPÓSIO LEITE NOS TRÓPICOS: NOVAS ESTRATÉGIAS DE PRODUÇÃO, 1989, Botucatu. Anais... Botucatu: FMVZ-UNESP, 1989. p.38-89.

HINCKLEY, L.S. Somatic cell count in relation to caprine mastitis. Vet. Med., v.78, p.267-1271, 1983.

ISHIWATA, T.; UETAKE, K.; EGUCHI, Y. et al. Physical conditions in a cattle vehicle during spring and autumn conditions in Japan, and reactions of steers to long distance transport. Anim. Sci. J., v.79, p.620-627, 2008.

LANDMANN, R.M.; MULLER, F.B.; PERINI, C. et al. Changes of immunoregulatory cells induced by psychological and physical stress: relationship to plasma catecholamines. Clin. Exp. Immunol., v.58, p.127-135, 1984.

MARNET, P.G.; McKUSIC, B.C. Regulation of milk ejection and milkability in small ruminants. Livest. Prod. Sci., v.70, p.125-133, 2001.

McDONALD, L.E.; PINEDA, M.H. Veterinary endocrinology and reproduction. 4.ed. Philadelphia: Lea \& Febiger, 1989. 571p.
NEGRÃO, J.A.; MARNET, P.G. Milk yield, residual milk, oxytocin and cortisol release during machine milking in Gir, Gir x Holstein and Holstein cows. Reprod. Nutr. Dev., v.46, p.77-85, 2006.

NUTRIENT requirements of small ruminants: sheep, goats, cervids, and new world camelids. Washington: National Academic of Sciences, 2007. 384p.

NWE, T.M.; HORI, E.; MANDA, M. et al. Significance of catecholamines and cortisol levels in blood during transportation stress in goats. Small Rumin. Res., v.20, p.129135, 1996.

ODORE, R.; D'ANGELO, A.; BADINO, P. et al. Road transportation affects blood hormone levels and lymphocyte glucocorticoid and $\beta$-adrenergic receptor concentrations in calves. Vet. J., v.168, p.297-303, 2004.

PAIVA, F.A.; NEGRÃO, J.A.; BUENO, A.R. et al. Efeito do manejo de fornecimento de colostro na imunidade passiva, cortisol e metabólitos plasmáticos de bezerros Holandeses. Arq. Bras. Med. Vet. Zootec., v.58, p.739-743, 2006.

PEAKER, M.; BLATCHFORD, D.R. Distribution of milk in the goat mammary gland and its relation to the rate and control of milk secretion. J. Dairy Res., v.55, p.41-48, 1988.

PEARSON, A.J.; KILGOUR, R. The transport of stock - an assessment of its effects. In: WODZICKATOMASZEWSKA, M; EDEY, T.N.; LYNCH, J.J. (Eds.). Behaviour in relation to reproduction, management and welfare of farm animals. Queensland Armidale, NSW: University of New England, 1980.

PETERS, M.D.P.; SILVEIRA, I.D.B.; RODRIGUES, C.M. Interação humano e bovino de leite. Arch. Zootec., v.55, p.923, 2007.

PORCIONATO, M.A.F.; NEGRÃO, J.A.; LIMA, M.L.P. Produção de leite, leite residual e concentração hormonal de vacas Gir $\times$ Holandesa e Holandesa em ordenha mecanizada exclusiva. Arq. Bras. Med. Vet. Zootec., v.57, p.820-824, 2005 .

RUSHEN, J.; MUNKSGAARD, L.; MARNET, P.G. et al. Human contact and the effects of acute stress on cows at milking. Appl. Anim. Behav. Sci., v.73, p.1-14, 2001.

SANHOURI, A.A.; JONES, R.S.; DOBSON, H. The effect of different types of transportation on plasma cortisol and testosterone concentrations in male goats. Br. Vet. J., v.145, p.446-450, 1989.

THIRY, E.; SALIKI, J.; BUBLOT, M. et al. Reactivation of infectious bovine rhinotracheitis virus by transport. Comp. Immunol., Microbiol. Infect. Dis., v.10, p.59-63, 1987.

YAGI, Y.; SHIONO, H.; CHIKAYAMA, K. et al. Transportation stress increases somatic cell counts in milk, and enhances the migration capacity of peripheral blood neutrophils of dairy cows. J. Vet. Sci., v.66, p.381-387, 2004.

ZENG, S.S.; ESCOBAR, E.N. Effect of parity and milk production on somatic cell count, standard plate count and composition of goat milk. Small Rumin. Res., v.17, p.269274, 1995. 